\title{
The Study on Strategies of College Mathematical Modeling Education
}

\author{
Xudong $\mathrm{Li}^{*}$ \\ Zhonghuan Information College, Tianjin University of Technology, Tianjin,300380, China; \\ arnold0110@sina.com \\ ${ }^{*}$ The corresponding author
}

\begin{abstract}
Keywords: Mathematical modeling; Teaching strategies; Innovation ability
\end{abstract}
\begin{abstract}
College students' mathematical modeling competition as an effective way to innovate mathematics education in colleges and universities, has great implications for improving college students' innovation ability and college mathematics education reform. This paper deeply analyzes the characteristics, roles of the national college students' mathematical modeling competition, the current students' ability and teachers' quality, to expound the outstanding problems in current mathematics education of college students. On this basis, several problems be paid attention to in the teaching of university mathematics modeling are analyzed, and then the corresponding solution strategies are put forward.
\end{abstract}

\section{Introduction}

In recent years, when actively exploring the effective measures to deepen the reform of mathematics education in colleges and universities, the vigorous development of the national college students mathematical modeling competition in majority of colleges and universities has aroused the concern of many experts and scholars. The National Mathematical Contest in Modeling (MCM) is jointly organized by the Higher Education Department of the Ministry of Education and the China Society for Industry and Applied Mathematics (CSIAM), held annually, It is one of the four major competitions for all colleges and universities in the country. The The purpose of the competition is to "encourage students to learn mathematics, improve the comprehensive ability for students to solve the practical problems by establishing mathematical models and the use of computer technology, to encourage students to actively participate in extracurricular scientific and technological activities, for developing knowledge and cultivating the spirit of creativity and cooperation, further promoting the reform of mathematics teaching system, teaching content and methods."

The titles of the competition are generally derived from the actual problems with appropriate simplified processing of the engineering technology and management science and other aspects without prior standard answers, it is not necessary to master in-depth expertise in advance, and thus they have greater flexibility, much better for participants to give play to their ingenuity and creativity. The form of competition is that a team consisting of three college students free to collect, read reference, study and research, use computer, the Internet and any software (but do not discuss the competition title with anyone outside the team) to complete a dissertation by the division of labor within three days. The award criteria are the rationality of the assumptions, the creativity of the modeling, the correctness of the results and the clarity of the text.

All countries in the world have attached great attention to the college students' mathematical modeling contest. University of Cambridge opened a mathematical modeling course for the graduate students in the late 1970, at the same time, some developed countries in Europe and America began to plan the content of mathematical modeling into education program of graduate students, college students and even high school students, and in 1983 they began to hold Two Yearly "Mathematical Modeling Teaching and Application International Conference" for regular communication. Mathematical modeling teaching and its various activities are developing rapidly and become one of the main directions of contemporary mathematics education reform. China began to set "mathematical model" course in Tsinghua University and some other colleges in the middle 1980. Experts and scholars 
at home and abroad have always believed that the college students mathematics modeling education and competition activities are the largest in scale and most successful practice of mathematics teaching reform in recent years. Through launching the colleges students mathematics modeling education and practice, It is not only beneficial to strengthen the accumulation of knowledge, more importantly, able to effectively improve the comprehensive ability and cultivate the scientific literacy of college students..

\section{The Characteristics of Mathematics Modeling Competition}

It is generally believed that the mathematical model is the mathematical simplification of the actual things, the abstract and simplified mathematical structure about some real world for a certain purpose, and the process of establishing the mathematical model is called mathematical modeling. Mathematical modeling is a practice of using mathematical methods to solve practical problems. It is to express the practical problems in mathematical ways, establish mathematical models and then use advanced mathematical methods and computer technology to solve them. Therefore, mathematical modeling is the process of describing the actual phenomenon in mathematical language.

The college students' mathematical modeling competition student-centered treating the practical problem as the main line, is a kind of college students' extracurricular scientific and technological activities aiming at cultivating students' innovation ability, and it has the following characteristics:

Openness and Initiative. The solution process, the solution tools and the results of the students' mathematical modeling contest are open. It focuses on cultivating students' innovative consciousness, innovative spirit and innovative thinking, thus breaking through the traditional teaching methods where teachers and teaching materials are the center, greatly mobilizing students' enthusiasm of study, and strengthening the students' practical ability.

Comprehensiveness and Applicability. College students' mathematical modeling activities are comprehensive and strong learning and training, which can effectively integrate the students' knowledge structure and further promote their initiative and enthusiasm for learning the follow-up courses. The titles of college students' mathematics modeling contest are coming from engineering technology and social economic life. It embodies that mathematics are derived from practice and work for practice. It has reached the organic combination of theory and practice.

Challenging and Interesting. Solving the problems from mathematical modeling contest is a comprehensive examination of college students' mathematical knowledge, computer knowledge, discovery and problem solving ability, information collection ability, writing ability and cooperation ability, etc. It holds great challenging. The contest is highly participatory, enabling students to learn in the activity and create a sense of pleasure and pride, so that the boring sense of mathematics is well restrained.

\section{The Current Problems of College Students' Mathematics Modeling Contest}

Students are encouraged and guided to participate in the national college students mathematical modeling competition, and strive to obtain good results in the competition; At the same time, increasing the teaching reform and further expanding the mathematical modeling teaching results in practice are the goal of many colleges and universities in recent years. However, some problems are still reflected in the mathematical modeling contest and the teaching process.

The Problems in the Process of Mathematics Modeling Activities for Students. (1) Lack of Good Thinking Quality. If you want to solve a modeling problem well, you must have a good thinking quality, many college students do not or not fully hold the above thinking quality. Faced with mathematical modeling problems, they often lack the sufficient confidence. The contest process is not only a test of the students' mathematical modeling ability, but also a test of students' thinking quality. Therefore, the lack of good thinking quality is often a primary reason of failure to participate the contest or undesired result in the process of learning mathematics modeling for students.

(2) Lack of Mathematics Reading Ability. There are many other subject terminology often existing in mathematical modeling questions, while students rarely or even have not heard of these terms, so that 
they can' $t$ understand the meaning of the title, so then can' $t$ establish good mathematical model. Good mathematics reading ability is a necessary condition to solve the problem of mathematical modeling, the process will be blocked in all aspects of modeling if lack of this ability.

(3) Lack of the Ability to Transform Practical Problems into Mathematical Ones. Mathematical model problems are presented in a variety of forms. On a specific practical problem, it is another difficult problem for students to estimate what mathematical knowledge are associated with the practical problems and what kind of mathematical methods should be used to solve them.

The Existing Problems of teachers in the Process of Mathematics Modeling Activities. In the process of mathematical modeling contest and teaching, the teacher's roles are the instructor of the contest, the organizer of the teaching, the participant of the study and the consultant of the information. The modeling activities provide a field of hope for the student's subjective learning, creative learning and development learning, and also creates a broad stage for teachers' "professional" development simultaneously. The effectiveness of modeling activities depends on the overall quality of teachers to a large extent. The main problems that teachers facing in the process of guiding the competition are summarized as the following:

(1) The Concepts of Education and Teaching need to be Updated. In the process of mathematical modeling teaching, teachers must overcome the stereotypes of the old teaching ideas, update their own education and teaching concepts, attach the importance to both knowledge learning and practical activities, student-centered, cultivate students' ability to learn and develop students creativity awareness and ability. Teachers should respecting the autonomy of students, treating the teaching activities as a process with new problems occurring continually. Teachers and students have the equal attitude when solving the problem together, while teachers guide and help students to explore their own learning.

(2) The Knowledge System Needs to be Further Expanded. The openness and autonomy of mathematical modeling learning compel teachers to face the challenges of knowledge and ability, therefore, teachers only continue to tap the original knowledge system, broaden their knowledge areas, they can obtain the right of speech in the modeling teaching and better organize students to carry out modeling learning activities. But now the knowledge system of some of the teachers always stay in the original subject knowledge, difficult to adapt to the requirements of mathematical modeling teaching, even hard to say that the students can get effective guidance.

(3) Creativity and Scientific Awareness Need to be Improved. Creativity is an important aspect of teacher's ability. Each teacher must plan and implement their own teaching work according to the specific teaching content, teaching object and teaching environment. Besides, They must also make timely evaluation and adjustment, reflection and summary afterwards. As to the teaching of emerging mathematics modeling courses, many problems are still in the stage of exploration, there is no ready experience, in the face of many new problems and new difficulties without effective prediction, teachers must make timely decisions, make timely adjustments according to the actual situation of teaching and students' refection, which requires teachers full of creativity and can not copy the original routine in the way of teaching.

(4) The Role Needs to be Consciously Changed in Teaching Process. The function of teachers is to establish a basic conceptual framework, introducing the students into a certain situation and providing advice, method guidance and monitoring for students. At the same time, the role of teachers should be changed from concerning about the knowledge to concerning about the students, its role is mainly providing students with appropriate guidance and help in the theory and methods. At present, many teachers are still far from this level, which also needs to gradually change with the professional development of teachers..

\section{Solution Strategies}

In view of the above problems, the construction of college students 'mathematical modeling teaching strategy should start from the topic, we need to pay attention to the cultivation of students' mathematical 
thinking and mathematical modeling ability, and construct a reasonable and effective teaching model of college mathematics modeling. At the same time, we should note that we need to carry out hierarchy teaching according to the different conditions of students. Here a few of strategies are introduced, as for reference.

Principles of Mathematical Modeling Teaching. The selected topic has certain research value, which can answer or explain some kind of phenomenon and question, with important value to improve the students' autonomous learning ability, creative thinking ability and practical ability. Mathematical modeling topics must adhere to the principle of the problem in the choice of content, treating problem as the center to organize students' learning activities. These questions can be the extended extension of classroom materials; can also come from extracurricular natural or social problems. The process of solving the problem by modeling is the process of thinking, so the chosen modeling topic should give the student a problem situation, while the students need to use the combination of existing knowledge and thinking to activate the solution to solve the problem.

The Cultivation of College students' Mathematical Modeling Ability. The college students' mathematical modeling competition requires the modelers to have strong knowledge application ability and practical ability. Therefore, we should pay attention to the cultivation of college students' mathematical modeling ability. By teaching the specific thinking of modeling methods, we can cultivate the ability of students to solve the model. The traditional mathematics class and experimental teaching are strengthened. Through analogy and other methods, we can train the ability of students to observe and guess. In addition, by strengthening the mathematical language training, we can cultivate students' logicality of thinking. In the teaching process, teachers should treat knowledge structure as the main line, strengthening the logical thinking method of teaching to inspire and guide students' logical thinking, so that students can grasp the knowledge more scientific, systematic, which is conducive to the migration of their knowledge and the development of thinking ability.

Mathematical Modeling Teaching Strategies for College Students. Mathematical modeling teaching should apply the different levels of teaching strategies. Mathematical modeling of learning and mastery, using and deepening, should be proceeding and developed based the main line of model simulation, model conversion and model construction. In the process of cultivating mathematical modeling ability, the training and cultivation of imitation ability of mathematical modeling are indispensable. It should be noted how to introduce and use the mathematical model of others, and develop the ability of students how to use mathematical methods and techniques to derive answers from known mathematical models. Many mathematical problems are essentially the combination and transfer, update and conversion of practical problems corresponding to the mathematical model. Therefore, it is very important to train the mathematical model conversion ability in the teaching process of cultivating students' mathematical modeling ability. In order to cultivate the ability to construct the mathematical model, except for strengthening training and cultivation of the logical thinking ability and non-logical thinking ability, we also should enable students to master the principle, methods and laws of relevant technology as much as possible

\section{Conclusion}

The objects of mathematical modeling come from the daily life and engineering practice, having a very strong practical background. Through the mathematical modeling contest, not only the ability of college students to solve practical problems using theoretical knowledge can be improved, the students' theoretical knowledge are expanded, the team consciousness and practical ability are strengthened, but also are the level of teaching and research for teachers who participate in the competition training and counseling improved, it exhibits a very important significance and role. Based on the analysis of the characteristics, functions and existing problems of the current national college students' mathematical modeling competition, this paper puts forward the corresponding solution strategy, which holds certain reference value. 


\section{References}

[1] Goldin C, Shteingold. Systems of Representations and Development of Mathematical Concepts. National Council of Teachers of Mathematics, 2001, 7: 1-23.

[2] Armstrong.The influence of individual cognitive style on performance in management edueation.Educational Psyehology, 2017, 20(3):324-338.

[3] H.L.Swanson.Influence of metacognitive knowledge and aptitude on problem solving. Journal of Educational Psychology, 2015, 82(2):306-314.

[4] GreenoJ.G.Process of understanding in Problem solving.Cognitive theory. 2015, 2:74-83.

[5] J.Sweller.Cognitive load during problem solving:Effects on learning.Cognitive Science, 2012, $12: 257-285$ 